\title{
The Unique Endocrine Milieu of The Fetus
}

\author{
Delbert A. Fisher \\ Department of Pediatrics, University of California, Los Angeles School of Medicine, Harbor-UCLA Medical Center, \\ Torrance, California 90509
}

\begin{abstract}
Since the pioneering studies of Jost and colleagues four decades ago, there has been impressive progress in our understanding of the intrauterine endocrine milieu (1). Fetal endocrine physiology differs in many important ways from the endocrinology of postnatal life. It is characterized by a series of unique fetal endocrine organs, by a number of hormones or metabolites uniquely prominent in the fetal compartment, by the adaptation of several fetal endocrine systems to special intrauterine functions, and by mechanisms to neutralize the biological actions of several potent hormones critical for normal postnatal development (Table I). The following discussion is intended to provide a brief perspective of this unique environment.
\end{abstract}

\section{Fetal endocrine adaptations}

In several instances, fetal endocrine systems or hormones have been transiently diverted to subserve singular gestational or developmental roles.

Fetal adrenal and estrogen production. The best-known and -characterized fetal endocrine gland is the fetal adrenal, adapted in utero to function in collaboration with the placenta to produce estrogens. This system, the so-called fetoplacental unit, has been reviewed in several recent publications (1-6).

The fetal adrenal cortex is composed of two distinct anatomic zones, an inner "fetal" zone and an outer "definitive" zone. The fetal zone is deficient in $\Delta 5,3 \beta-01$ dehydrogenase/ $\Delta 4,5,3$-ketosteroid isomerase and has a high steroid sulfokinase activity (35). Thus, the conversion of pregnenolone to progesterone is limited and the major secretory product of the fetal adrenal is dehydroepiandrosterone sulfate (DHAS), ${ }^{1}$ an essentially inactive

Dr. Fisher is Professor of Pediatrics and Medicine at the UCLA School of Medicine.

Address reprint requests to Dr. Fisher, Department of Pediatrics, Harbor-UCLA Medical Center, 1000 West Carson Street, Torrance, CA 90509.

Received for publication 3 February 1986.

1. Abbreviations used in this paper: AVT, pituitary arginine vasotocin; CAT, catecholamines; CLIP, corticotropin-like intermediate peptide; CRF, corticotropin-releasing factor; CT, calcitonin; 1,25D, 1,25-dihydroxyvitamin D; DHAS, dehydroepiandrosterone sulfate; EGF, epidermal growth factor, FGF, fibroblast growth factor, FSH, follicle-stimulating hormone; GH, growth hormone; GnRH, gonadotropin-releasing hormone; GRF, growth hormone-releasing factor; hCC, human chorionic corticotropin; hCG, human chorionic gonadotropin; hCS, human chorionic somatomammotropin; hCT, human chorionic thyrotropin; LH, luteinizing hormone; MIF, testicular mullerian inhibiting factor; NE, norepinephrine; NGF, nerve growth factor; OT, oxytocin; OVT,

J. Clin. Invest.

(c) The American Society for Clinical Investigation, Inc.

0021-9738/86/09/0603/09 $\$ 1.00$

Volume 78, September 1986, 603-611 hormone precursor. DHAS is transported to the liver for 16hydroxylation and/or to the placenta, where it is hydrolyzed by a steroid sulfatase and utilized as substrate for placental estrogen biosynthesis. DHAS serves as substrate for placental estrone and estradiol production; $16 \mathrm{OH}-\mathrm{DHAS}$ is the major substrate for placental estriol synthesis (1-6). Estriol is a hormone unique to pregnancy; it is not secreted by the ovary of nonpregnant women.

There is evidence that placental chorionic gonadotropin (hCG) is an important stimulus to fetal adrenal function early in pregnancy; fetal pituitary adrenocorticotropin (ACTH) is essential for maintenance of fetal zone function by midgestation $(4,5,7)$. Other pro-opiomelanocortin (POMC)-derived peptides-alpha-melanocyte-stimulating hormone ( $\alpha$-MSH), corticotropin-like intermediate peptide (CLIP), and $\beta$-endorphinseem to have only limited roles $(4,5)$. Preliminary evidence suggests a possible role for epidermal growth factor (EGF) and fibroblast growth factor (FGF) both at the adrenal gland and pituitary levels $(5,8)$.

The human placenta at term secretes $10-25 \mathrm{mg} / \mathrm{d}$ of estradiol and $40-50 \mathrm{mg} / \mathrm{d}$ of estriol (3-6); estrogen production in nonpregnant women is less than $1 \mathrm{mg} / \mathrm{d}$. Most of the estrogen is secreted into the maternal circulation, but fetal concentrations and levels in amniotic fluid are quite high. To date, the signifcance of the enormous amounts of estrogen produced during pregnancy remains largely obscure both in the mother and fetus. Estriol is a relatively weak estrogen in many biological systems, but is active and may have a role in maintenance of uteroplacental blood flow (5). It is of interest that estrogen production and circulating estrogen levels (especially estriol) may be markedly reduced in pregnancies in which the fetus (including placenta) has x-linked steroid sulfatase deficiency, and the placenta is unable to convert DHAS to free DHA for estrogen biosynthesis; the fetus in such instances seems otherwise normal (3).

Fetal adrenal and parturition. The fetal adrenal plays a significant role in the timing of parturition in some mammalian species $(7,9-12)$. The events of parturition have been best characterized in sheep, in which species a marked prenatal fetal cortisol surge, dependent on the fetal pituitary, initiates a cascade of endocrine events (including decreased placental progesterone production, increased placental estrogen secretion, and increased production of prostaglandins) which eventuate in parturition (4, 5, 9-13). Fetal hypophysectomy prevents this sequence of events and delays parturition; however, the mechanism of the activation of the fetal adrenal remains unclear, ACTH does not increase in fetal blood prior to or during the rise in cortisol. The search

OT-AVT-like peptide; PGE and PGF, prostaglandins E and F; PNMT, phenylethanolamine $N$-methyl transferase; POMC, pro-opiomelanocortin; PRL, prolactin; $\mathrm{rT}_{3}$, reverse triiodothyronine; SRIF, somatotropin release inhibiting factor; $S T H$, second trophic hormone; $T_{3}$, triiodothyronine; $\mathrm{T}_{4}$, thyroxine; TRH, thyrotropin-releasing hormone; TSH, thyroid-stimulating hormone; VP, vasopressin. 
Table I. Features of the Fetal Endocrine Environment

Unique fetal endocrine adaptations
Fetal adrenal
Estrogen production
Parturition
Fetal maturation
Fetal testes
Sex differentiation
Neurohypophyseal system
Fetal water metabolism
Fetal stress
Parturition?
Parathyroid-calcitonin system
Placental calcium transport
Bone mineral anabolism?
Unique fetal endocrine systems
Paraaortic chromaffin system
Fetal intermediate pituitary
Placental progesterone system
Ectopic polypeptide hormones
Extrahypothalamic neuropeptides
Neutralization of hormone actions in the fetus
Production of inactive metabolites
Receptor/postreceptor immaturity

for a second trophic hormone (STH) for the fetal zone continues. Hormones considered include $\mathrm{ACTH}_{1-38}, \mathrm{ACTH}_{1-24}$, $\mathrm{ACTH}_{1-13}, \mathrm{ACTH}_{18-38}, \beta$-endorphin, prolactin, estrogens, $\alpha$ MSH, CLIP, EGF, and FGF $(4,5,13)$. However, the putative STH remains elusive.

In human and primate species a role for fetal cortisol as a trigger for parturition is less clear. Fetal cortisol levels do not increase markedly, progesterone concentrations do not consistently fall, and changes in estrogen levels are variable $(4,5,10)$. However, there is a rise in fetal plasma DHAS in primates prior to spontaneous delivery, and maternal administration of dexamethasone in this species significantly delays parturition $(4,5)$. In humans, anencephaly or fetal adrenal hypoplasia also prolong gestation (13). There is an increase in cord plasma cortisol during the last 3-5 wk in human neonates (13-15), and this increase is more marked in infants delivered vaginally or by cesarean section of women in labor $(14,15)$. Whether these changes represent a cause or effect of labor remains to be determined (13).

Much current work is focused on the mechanisms of activation of prostaglandin production. Prostaglandin E (PGE) synthesis in human amnion can be stimulated by a fetal urinary EGF-like activity, by platelet-activating factor, and by catecholamines; in decidua, PGE synthesis is increased by catecholamines and by estrogen (11). Modulators of calcium regulate PGE production in both systems, and calcium seems to be required for PGE stimulation by $\beta$-adrenergic agonists (11). Local amnion and decidual production of estrogen and progesterone (which inhibits prostaglandin production) also may be involved in regulation of prostaglandin production from amnion or decidua as well as prostaglandin production from endometrium (11). Conversion of PGE to prostaglandin F (PGF) seems to occur in chorionic tissue.

Fetal cortisol as a maturational hormone. Cortisol serves as an important maturational stimulus to prepare the fetus for extrauterine survival. The fetal cortisol surge serves to $(a)$ augment surfactant synthesis in lung tissue (14-17), (b) increase insulin, $\beta$-adrenergic, and EGF receptors in fetal lung tissue (18-20), (c) increase adrenal medullary phenylethanolamine $N$-methyl transferase activity (to augment epinephrine biosynthesis from norepinephrine) $(5,16),(d)$ increase hepatic iodothyronine beta (outer) ring monodeiodinase (to augment thyroxine $\left[\mathrm{T}_{4}\right]$ conversion to triiodothyronine $\left.\left[\mathrm{T}_{3}\right]\right)(21),(e)$ decrease sensitivity of the ductus arteriosus to prostaglandin (to facilitate ductal closure) $(22),(f)$ mature secretory function of the rat fetal pancreas (23), $(g)$ induce maturation of numerous small bowel enzymes and transport processes $(24,25)$, and $(h)$ induce maturation of a variety of hepatic enzymes $(5,16)$. In some instances these events involve stimulation by cortisol of synthesis of the specific protein or enzymes; in other instances (e.g., the increased sensitivity of the ductus arteriosus to prostaglandin) the mechanism of the cortisol effect remains obscure.

Fetal testes and sexual differentiation. The fetal gonads have little or no metabolic role during fetal life. Instead the fetal testes, under the influence of the placenta, serve at a critical period of embryogenesis to induce male sexual differentiation $(26,27)$. Human chorionic gonadotropin (hCG), a luteinizing hormone (LH)-like placental hormone, stimulates fetal testicular androgen production between 8 and 16-18 wk gestation. The testicular androgen, in turn, stimulates development of the embryonic wolffian duct system and the external genitalia to effect male differentiation.

In addition, the fetal testes produce an inhibitor of mullerian duct differentiation, mullerian-inhibiting factor or MIF (28-30). This substance, the existence of which was first proposed by Jost, appears to be a glycoprotein with a monomer molecular weight of 72,000 and multimer molecular weights ranging from 145,00 to $235,000(27-30)$. The structure has not yet been characterized and information regarding its mechanism of action is limited. It has been shown that mullerian duct regression, in vitro, requires a 24-36-h exposure to MIF, and that MIF acts extracellularly by causing dephosphorylation of a membrane protein (31); its intracellular effect appears to be inhibited by cyclic AMP (cAMP) (32).

Fetal ovarian hormone secretion plays little or no role in sexual differentiation; in a female fetus or an agonadal fetus, the wolffian ducts regress in the absence of testicular androgen, and normal female development of the mullerian ducts and external genitalia occurs $(26,27)$.

Neurohypophysis and fetal water metabolism. The fetal neurohypophysis is well developed by 10-12 wk of gestation and contains measurable concentrations of both vasopressin (VP) and oxytocin (OT) (33). In addition, arginine vasotocin (AVT), the parent neurohypophyseal hormone in submammalian vertebrates, has been identified in the fetal pituitary and pineal glands as well as in adult pineal of several mammalian species, including humans (34-36). AVT is present in the pituitary gland only during fetal life, disappearing in the neonatal period; this has been cited as an example of ontogeny recapitulating phylogeny (34). In adult mammals AVT instilled into the cerebrospinal fluid inhibits anterior pituitary gonadotropin and ACTH release, stimulates prolactin release, and induces sleep; however, its physiologic importance in these regards remains unclear (35). No role for AVT in the fetal pineal gland has been proposed.

Data regarding fetal VP secretion have been derived largely from the sheep model (33). In this species baseline fetal plasma VP concentrations are similar to maternal levels after midgestation. During the last trimester of gestation fetal hypothalamic- 
pituitary responsiveness to both volume and osmolar stimuli for VP secretion are well developed, and an antidiuretic effect of VP on the fetal kidney is well established $(33,37,38)$. Baseline plasma levels of AVT in fetal sheep during the last trimester approximate values for VP and OT (36). Presumably this AVT is derived from the posterior pituitary. However, the stimuli for AVT secretion in the fetus remain to be defined.

It is clear that both VP and AVT can inhibit fetal to maternal water transfer across the placenta in response to an acute maternal osmolar load (39). In addition, both VP and AVT inhibit fetal lung fluid production as well as fetal renal free water clearance (40-42). VP also may have an effect on water transport via the amniotic membranes (43). Thus, available evidence suggests that both hormones act in the fetal environment to conserve water for the fetus, inhibiting flow across the placenta and loss into amniotic fluid via the lungs as well as the kidneys. Whether AVT exerts its effects via VP receptors or separate fetal AVT receptors is not clear.

Neurohypophysis and stress. In the fetus, VP also appears to function as a stress hormone. Perhaps the major potential stress for the fetus is hypoxia, and recent evidence indicates that the VP response to hypoxia is greatly augmented relative to the maternal response and relative to the fetal VP responses to osmolar stimuli (44-46). Elevated plasma VP concentrations also have been observed in human cord blood in association with intrauterine bradycardia and meconium passage (47), and correlations with other parameters suggestive of hypoxia, including low $\mathrm{pH}$ and acidosis, have been reported (45). There is evidence that the vasopressor action of VP may be important in the maintenance of fetal circulatory homeostasis during hemorrhage and a similar role is possible for hypoxia (48). Fetal hypoxia also is a major stimulus for catecholamine release $(49,50)$. However, we have little information regarding interaction between VP and catecholamines during fetal hypoxia. In addition, fetal hypoxia and AVT are known to stimulate anterior pituitary function $(35,50,51)$. A role for VP as a corticotropin-releasing factor (CRF) is well established in the adult, but the significance of VP or AVT as a CRF in the fetus has not been explored.

Neurohypophysis and parturition. Basal plasma OT concentrations in the fetal sheep are low, approximating baseline VP and AVT levels throughout gestation $(52,53)$. Maternal plasma OT levels also remain low until the second stage of labor at which time concentrations increase 20-30-fold $(33,53)$. Cervical and/or vaginal distension have been postulated as the stimuli for maternal OT release during late stage 2 labor. Fetal plasma OT levels are increased only immediately prior to delivery; stress in the final moments of labor or early neonatal life may be responsible (53). The patterns of maternal and fetal plasma OT levels during human pregnancy and delivery are similar to the patterns in sheep $(54,55)$. Thus, there is no convincing evidence for a role of maternal OT in initiating parturition and little evidence that fetal OT plays a significant role in labor. A role for OT in postpartum hemostasis has been proposed (53), and a milk ejection role for OT in postpartum lactation is well documented $(56,57)$.

The plasma of pregnant women also contains an immunoreactive OT-AVT-like material (OVT), which behaves on high pressure liquid chromatography similarly but not identically to OT $(58,59)$. This novel putative peptide is present in low concentrations in plasma of men and nonpregnant women, and levels in both increase in response to estrogen administration (58). Baseline OVT levels exceed the concentrations of VP and
AVT during pregnancy and OVT has been identified in newborn cord blood $(59,60)$. The high levels in pregnancy presumably are estrogen stimulated. OVT probably accounts for the high concentrations of immunoreactive OT previously measured in pregnant women by several earlier investigators $(58,59)$.

Fetal parathyroid, calcitonin, and calcium homeostasis. The fetal parathyroid glands and the thyroid parafollicular " $\mathrm{C}$ cells," the calcitonin-secreting cells, are identifiable at the end of the first trimester, and both endocrine systems are functional during the second and third trimesters. Most of our information regarding fetal calcium homeostasis has been obtained from studies of the fetal sheep and monkey models and measurements in human preterm and term infants $(61,62)$. In all these species during pregnancy, high concentrations of fetal calcium (averaging $11-12 \mathrm{mg} / \mathrm{dl}$ in the last trimester) are maintained by active placental transport from maternal blood (61). Parathyroid hormone (PTH) levels in human cord blood during the last trimester are relatively low and calcitonin (CT) concentrations are high (61, 62). 25-Hydroxyvitamin D and 1,25-dihydroxyvitamin D $\left[1,25(\mathrm{OH})_{2} \mathrm{D}\right](1,25 \mathrm{D})$ are transported across the placenta, and free vitamin $\mathrm{D}$ concentrations in the fetal circulation are similar to maternal values (61-63). It is postulated that the high prevailing levels of total and ionized calcium maintained in fetal blood by active maternal to fetal transport tend to suppress fetal PTH and stimulate CT secretion $(61,62)$.

Recent studies in the fetal sheep model show that fetal thyroparathyroidectomy results in a rapid decrease in fetal plasma calcium concentration and a loss of the placental calcium gradient (64). Fetal nephrectomy also reduces fetal calcium concentrations and the hypocalcemia can be prevented by administration of $1,25 \mathrm{D}(64,65)$. These data support the hypothesis that the action of PTH in the fetus involves stimulation of renal production of $1,25 \mathrm{D}$ which acts to promote maternal-fetal transport of calcium by the placenta. There is no doubt that the fetal kidney can synthesize $1,25 \mathrm{D}$, and the placenta contains specific 1,25D receptors as well as a vitamin D-dependent calcium-binding protein $(63,64)$. Moreover, infusion of antibody to $1,25 \mathrm{D}$ into the sheep fetus results in a loss of the placental calcium gradient (64).

However, several observations are confounding. In the thyroparathyroidectomy experiments $1,25 \mathrm{D}$ in fetal plasma did not change and PTH infusion did not correct the fetal hypocalcemia (64). In addition, in the fetal nephrectomy study fetal plasma phosphorus increased significantly (65). The significance of these observations remains unclear, but a direct role for PTH in placental calcium transport has been postulated (64), and a role for $1,25 \mathrm{D}$ or perhaps $24,25(\mathrm{OH})_{2} \mathrm{D}$ in fetal bone mineral accretion is possible (66).

High blood levels of CT are maintained in the fetus, perhaps because of the chronic stimulation of fetal hypercalcemia; CT is responsive to calcium in the sheep and primate fetus and in the newborn infant $(61,62)$. In that a prominent effect of CT is to inhibit bone resorption, the high fetal serum calcium concentrations coupled with high circulating CT would promote bone mineral anabolism (67). CT has been called a vestigial hormone because of its limited role in postnatal calcium regulation (67). It may have an important role in the fetus.

\section{Unique fetal endocrine systems}

There are several endocrine systems unique to fetal life. Among the first of these to be recognized was the paraaortic chromaffin system. 
Paraaortic chromaffin system. In the human fetus the sympathetic nerve trunks and the paired adrenal medullary masses are well developed by 10-12 wk of gestation. In addition, there are numerous extramedullary paraganglia (derived from preaortic condensations of sympathetic neurons and chromaffin cells) scattered throughout the abdominal and pelvic sympathetic plexuses (68). Most of the chromaffin tissue in the fetus is represented by these extramedullary paraganglia which may reach a maximum size of 2-3 mm in diameter by 28-30 wk of gestation. The largest of these paraganglia, the organs of Zuckerkandl, near the origin of the inferior mesenteric arteries, enlarge to $10-15 \mathrm{~mm}$ in length at term. After birth the paraganglia gradually atrophy, disappearing completely by 2-3 yr of age.

Catecholamines (CAT) are present in the paraaortic chromaffin tissue by 10-15 wk of gestation and concentrations increase to term (69). The predominant CAT is norepinephrine (NE), presumably because of low activity of phenylethanolamine $N$-methyl transferase (PNMT) in paraaortic chromaffin tissue. PNMT, which catalyzes the methylation of NE to epinephrine, appears to be activated by the high concentrations of cortisol in the adrenal medulla; in contrast to the adrenal medulla, cortisol levels are low in extramedullary chromaffin tissue $(5,16)$. In fetal sheep the chromaffin cells of the adrenal medulla can respond directly to asphyxia with NE secretion long before splanchnic innervation develops (49), and it is likely that the noninnervated paraaortic tissue responds similarly. Thus the ovine fetus responds to stress with augmented and predominant NE secretion (70, 71). The augmented CAT response to birth in the human neonate presumably also depends, at least in part, on paraganglial CAT secretion (72-75).

Both chromaffin cells and sympathetic nerve cells are derived from common neuroectodermal stem cells and both are responsive to nerve growth factor (NGF) $(76,77)$. Sympathetic nervous system ontogenesis is known to be NGF dependent, and recent evidence indicates that injections of NGF antiserum into neonatal rats leads to degeneration of immature chromaffin cells as well as primitive sympathetic cells and pheochromoblasts (77). Whether NGF and other growth factors are involved in the transient lifespan and function of the paraganglia in the human fetus and neonate remains to be clarified.

Fetal intermediate pituitary. In the human and sheep fetus an intermediate lobe of the pituitary is prominent in addition to the anterior and posterior lobes $(51,78,79)$. Intermediate lobe cells begin to disappear near term and are virtually absent in the adult human pituitary although the intermediate lobe in the adult of lower species is anatomically and functionally distinctive $(51,78)$. This may be another example of ontogeny recapitulating phylogeny. The major secretory products of the intermediate lobe are $\alpha$-MSH and $\beta$-endorphin derived from cleavage of the POMC molecule. POMC in the anterior lobe is cleaved predominantly to ACTH and $\beta$-lipotropin.

In rhesus monkeys and humans, the fetal pituitary, in contrast to the adult gland, has been shown to contain high concentrations of $\alpha$-MSH and CLIP $(80,81)$; and $\alpha$-MSH concentrations in the human fetus decrease progressively with increasing fetal age (82). Moreover, the circulating levels of both $\beta$-endorphin and $\beta$-lipotropin are high in the fetal lamb, and the basal ratio of $\beta$-endorphin to $\beta$-lipotropin levels is greater than that during hypoxic stimulation of the anterior pituitary, suggesting a fetal intermediate lobe origin of basal $\beta$-endorphin levels in the fetus (51). A role for $\alpha$-MSH and CLIP in fetal adrenal ac- tivation has been proposed, as well as a role for $\alpha$-MSH in fetal growth $(5,7,51,83,84)$.

Placental production of progesterone. During normal pregnancy there is a marked and progressive increase in progesterone production. The maternal corpus luteum is the major source of the increased plasma progesterone concentrations during the first 5-6 wk; after 12 wk the placenta is the major source $(3,4)$. The principal substrate for placental progesterone synthesis is circulating maternal low density lipoprotein (LDL) cholesterol; the placenta does not have the capacity to synthesize cholesterol from acetate. Placental progesterone production occurs independently of the maternal pituitary or adrenal glands, and fetal death in utero has little acute effect on maternal progesterone levels (3). Placental gonadotropin (hCG) may have a role in autoregulation of progesterone synthesis $(5,85)$.

The production of progesterone approximates $250 \mathrm{mg}$ daily during the third trimester, a value some 10 -fold greater than that during the midluteal phase of the normal menstrual cycle, and $90 \%$ of this is secreted into the maternal circulation (3-5). This progesterone serves a role in maintaining the uterine musculature in a state of quiescence; there also is evidence for a role in inhibiting maternal cell-mediated immune responses to foreign (fetal) antigens (5). In spite of the predominant secretion of progesterone into the maternal circulation, fetal blood progesterone levels are some sevenfold higher than maternal values (5). The significance of this progesterone to the fetus is not clear.

Ectopic production of pituitary-like hormones. The placenta has long been known to be an important source of several polypeptide hormones unique to pregnancy $(5,85-87)$. The most important are hCG and human chorionic somatomammotropin (or placenta lactogen) (hCS). hCG is a glycoprotein of 36,000 $40,000 \mathrm{~mol} \mathrm{wt}$ with structural, biological, and immunological similarities to the pituitary gonadotropins and thyrotropin; hCG also has weak thyrotropic hormonelike activity $(5,85)$. hCS is a 191-amino acid protein having $96 \%$ homology with human pituitary growth hormone $(\mathrm{GH})(5,86)$. It has $3 \%$ or less of the growth-promoting bioactivity of $\mathrm{GH}$ and equivalent prolactinlike effects. hCG is secreted predominantly during the first half of gestation and hCS during the latter half. The predominant roles of hCG seem to be the maintenance of the corpus luteum, stimulation of the fetal testes, stimulation of the fetal adrenal cortex, and stimulation of placental progesterone production $(5,85)$. hCS, like $\mathrm{GH}$, has anti-insulin action and has been proposed to exert an anti-insulin effect on maternal carbohydrate and lipid metabolism $(5,86)$. This effect would tend to increase maternal glucose and amino acid levels and augment maternal to fetal substrate flow.

Recombinant DNA studies of the glycoprotein hormone family have shown a single gene for the $\alpha$-subunit expressed in the placenta for hCG and in the pituitary for production of LH, follicle-stimulating hormone (FSH), and thyroid-stimulating hormone (TSH) (88). Also, there is a single gene for the $\beta-\mathrm{LH}$ subunit whereas there are seven hCG $\beta$-subunit genes or pseudogenes. These and the $\beta$-LH gene have very similar structures, and it seems that $\beta$-hCG arose from $\beta$-LH and that the $\beta$-hCG gene family is early on the process of evolution of pseudogenes (88). The prolactin (PRL), GH, and hCS genes also are closely related (89-91). PRL is presumed to be the ancestral gene; GH evolved nearly 400 million years ago and hCS within the last 10 million years (89). The GH gene cluster includes five similar gene loci, two for GH and three for hCS; these have 95\% mRNA 
homology and are presumed to have arisen by repeated duplications over time $(90,91)$. Only two of the hCS sequences are expressed in the placenta producing identical hCS molecules $(90,91)$.

The human placenta synthesizes a chorionic corticotropin (hCC); in addition, $\beta$-endorphin, $\alpha$-MSH, and $\beta$ - and $\alpha$-lipotropin have been isolated from placental tissue $(7,51,92-95)$. Thus the placenta, like the pituitary gland appears to synthesize a POMC. The placenta may contribute to the slightly increased maternal levels of ACTH in late gestation and to the resistance to ACTH suppression with glucocorticoid at this time, because placental ACTH is not suppressed by glucocorticoid (7). There is some evidence in pregnant monkeys that maternal adrenal function may be regulated in part by the placenta (96).

There also is evidence that the placenta produces a chorionic thyrotropin (hCT) (97-99). Maternal plasma levels of hCT are very low in normal pregnancy and appear to be of little physiologic significance (99). Most of the thyrotropic activity in placental tissue and in maternal plasma during pregnancy seems attributable to the inherent TSH bioactivity of hCG (99).

Fetal tissues also are capable of producing an hCG-like material. Studies of kidney, liver, and testes from 16-20-wk human fetuses incubated in vitro have demonstrated production of immunoreactive and bioactive hCG $(5,100-102)$. Kidney tissue demonstrated nearly half the hCG production (per milligram of protein) of placental extracts; liver activity was much lower.

ACTH-like immunoreactivity has been demonstrated in a wide variety of adult tissues and has been shown in relatively high concentrations in neonatal rat pancreas and kidney (103). Presumably this is derived from a POMC parent molecule, but this has not yet been demonstrated.

Extrahypothalamic neuropeptide production. Hypothalamic neuropeptides have been demonstrated in a wide variety of adult tissues (104-107). In the fetal environment, such neuropeptides are predominantly localized to placental and gut tissues. The human placenta contains/produces gonadotropin-releasing hormone (GnRH), thyrotropin-releasing hormone (TRH), somatotropin release inhibiting factor (SRIF or somatostatin), corticotropin-releasing factor (CRF), and growth hormone-releasing factor (GRF) (51, 108-112).

Chorionic GnRH is the best studied of the placental neuropeptides. Although the peptide has not yet been purified and structurally characterized, high pressure liquid chromatography studies have shown that chorionic $\mathrm{GnRH}$ is similar or identical to synthetic hypothalamic GnRH (108). It is produced in the cytotrophoblast and can bind to receptors in the syncytiotrophoblast $(108,113)$. It is interesting that the placental GnRH receptor has lower affinity and less selectivity for GnRH analogues than the pituitary receptor (113). Because synthetic GnRH increases in vitro production of hCG, progesterone, estrone, estradiol, and estriol from placental explants, endogenous chorionic $\mathrm{GnRH}$ has been postulated to have a paracrine role in the regulation of placental hCG and steroid hormone production (108).

The placental TRH immunoreactivity has not been completely characterized nor has its site of production (108). Immunoreactive chorionic SRIF, like GnRH, has been localized to the cytotrophoblast. The observations that the SRIF containing cells in the placenta disappear as pregnancy progresses and that hCS production increases progressively during the latter half of gestation led to the speculation that chorionic SRIF may exert a paracrine action on production of hCS by the syncytiotrophoblast (108). No data for or against this hypothesis are available presently.

Immunoreactive CRF has been identified in placental extracts and in third trimester pregnancy plasma (111). It was not detected in plasma of pregnant women during the first or second trimesters and disappeared postpartum. The physiochemical similarity of CRF in placenta and plasma and the timing of the appearance of CRF in pregnancy plasma suggested a placental source for the circulating peptide and a possible role of placental CRF in the regulation of maternal pituitary ACTH secretion late in gestation (111).

Immunoreactive and biologically active GRF has been identified in rat placenta (112). Two forms of GRF activity were identified by high pressure liquid chromatography, one eluting identically to synthetic GRF and one similarly to the methionine sulfoxide analogue.

Particularly high concentrations of TRH, SRIF and CRFlike immunoreactivity have been observed in neonatal rat pancreas and gastrointestinal tract tissues at a time when similar hypothalamic concentrations of immunoreactivity are low (114 117). These neuropeptides have immunoreactive and chromatographic properties similar to those of the synthetic hypothalamic peptides (114-117). In the case of TRH, encephalectomy did not alter the relatively high circulating TRH levels in the neonatal rat whereas significant reductions were produced by pancreatectomy (114). Similar preliminary observations have been reported for CRF in the neonatal rat (116). TRH production from monolayer cultures of fetal rat pancreatic cells has been studied and found to be stimulated by serotonin and inhibited by carbachol; catecholamines, gamma aminobutyric acid or histamine had no effect (117). Specific neurotransmitter control was postulated.

Both TRH and SRIF levels are elevated in blood of the human neonate $(115,118,119)$ and significant concentrations of a TRH-like neuropeptide have been demonstrated in human neonatal pancreas (120). Thus, an endocrine role for these neuropeptides has been postulated in the fetal and neonatal periods.

There is a general tendency to hypersecretion of fetal pituitary hormones in the sheep during the last half of gestation, and high cord blood levels of pituitary hormones have been well documented in aborted fetuses and premature human infants; these include GH, TSH, ACTH, $\beta$-endorphin, $\beta$-lipotropin, $\mathrm{LH}$, and FSH $(51,118,121,122)$. Maturation of hypothalamic-pituitary control is complex and the mechanism of fetal pituitary hyperfunction is not yet clear; immaturity of higher nervous system inhibitory input has been postulated for GH $(121,122)$, and immature negative feedback control clearly plays a role for TSH and the gonadotropins $(118,122)$ and perhaps for ACTH (122). However, a role for extrahypothalamic neuropeptides has not been excluded.

\section{Neutralization of hormone action in the fetus}

Production of inactive metabolites. As indicated earlier, fetal cortisol functions as an important maturational hormone late in pregnancy. A role for cortisol in the fetus earlier in gestation has not been established. The placenta is permeable to steroid hormones but contains an isomerase that converts most of the cortisol to inactive cortisone $(4,15)$. Additionally, although many adult tissues are capable of converting cortisone to cortisol, fetal tissues seem devoid of this capacity during most of fetal life (4, 
15). Thus, most of the cortisol that crosses the placenta or is produced by the fetus is inactivated to cortisone by the placenta or by fetal tissues. Teleologically, this would help preserve the anabolic and growth-promoting milieu of the fetus and minimize premature maturational and parturitional effects of cortisol.

Thyroid hormones also appear to have limited actions during fetal life. The athyroid human fetus is born normally grown and usually without detectable stigmata of thyroid hormone deprivation (123-125). Treatment with thyroid hormone early after birth leads to normal physical and mental growth and maturation $(126,128)$. Fetal thyroid hormone metabolism is characterized by conversion of $\mathrm{T}_{4}$ to inactive reverse triiodothyronine $\left(\mathrm{rT}_{3}\right)$ and by limited receptor/postreceptor responsiveness to thyroid hormone. The placenta contains an iodothyronine inner ring monodeiodinase which converts any maternal $T_{4}$ to $r T_{3}$ (129). In addition, fetal liver and kidney, in contrast to adult liver and kidney, manifest little or no iodothyronine outer ring monodeiodinase activity so that there is little or no conversion of $T_{4}$ to active $T_{3}(21,125,130-132)$. As a consequence, serum $T_{3}$ levels in the fetus remain very low until the last few weeks of gestation $(118,125,130)$. Selected fetal tissues (brain, brown adipose tissue) have active iodothyronine outer ring monodeiodinase, but the significance is not yet clear (132).

Receptor or postreceptor immaturity. Recent data also suggest that fetal tissues are largely unresponsive to thyroid hormones. Fetal ovine liver, kidney, and brain thermogenesis (oxygen consumption, $\mathrm{Na} / \mathrm{K}$ ATPase activity, and mitochondrial alphaglycerophosphate dehydrogenase activity) are unresponsive to exogenous $T_{3}$ during the third trimester (133). Moreover, thyroid hormone responsive protein species appear to demonstrate thyroid hormone responsiveness only during the perinatal period; beta-adrenergic receptor binding in heart and lung of the ovine fetus is unresponsive to $T_{3}$ in the late third trimester but $T_{3}$ responsive in the neonatal period (134). Rat pituitary GH concentrations are thyroid hormone responsive only during the first weeks of extrauterine life (135). Mouse submandibular gland EGF and NGF levels become thyroid hormone responsive only during the second week of life $(136,137)$ as do urine and kidney EGF concentrations (137) and hepatic EGF receptor binding (138). Mouse skin EGF levels and skin EGF receptors are thyroid responsive during the first neonatal week $(139,140)$. The mechanism of this delayed thyroid hormone responsiveness is not yet clear, but delayed maturation of postreceptor responsiveness seems likely. Recent data indicate that thyroid hormone receptor binding sites in nuclear extracts of fetal-neonatal rat tissues ap- pear early in fetal life, much before the effects of thyroid hormone become manifest (141).

The effect of the high circulating concentrations of $\mathrm{GH}$ in the fetus also is minimal. Available evidence suggests that fetal somatic growth is not GH dependent; the GH-deficient fetus has little or no growth retardation $(121,122)$. In this instance there is a delayed maturation of $\mathrm{GH}$ receptors. In animals, including the sheep, hepatic GH receptor binding appears only during the neonatal period $(121,122,142)$. A deficiency of prolactin (PRL) receptors also may be a major factor in the apparently limited PRL bioactivity in the fetus near term; available receptor studies are limited $(121,122)$.

There is less information regarding fetal hormone responsiveness in other systems. Beta-adrenergic receptor binding in heart and lung of the sheep fetus are relatively low near term, and as indicated earlier, increase in the neonatal period in response to thyroid hormones (134). Moreover, premature lambs have an augmented plasma catecholamine surge at birth relative to term lambs and have a relatively obtunded increase in plasma free fatty acid levels, suggesting reduced catecholamine responsiveness (143). The extraordinarily high levels of progesterone and estrogens in fetal blood also seem to have limited effects in the fetus. Estrogen receptors are present in low concentration in fetal guinea pig kidney, lung, and uterus at midgestation and increase progressively to term (144). Uterine estrogen receptors in the rat appear to be synthesized during the first $10 \mathrm{~d}$ of life (145). There is limited information regarding maturation of postreceptor responses.

\section{Summary}

Table II summarizes in tabular form the major features of the fetal endocrine milieu discussed in the foregoing pages. The mammalian fetus develops in an environment where respiration, alimentation, and excretory functions are provided by the placenta. Fetal tissue metabolism is oriented largely to anabolism; body temperature is modulated by maternal metabolism, and fetal tissue thermogenesis is maintained at a basal level. Tissue and organ growth appear to be regulated by growth factors which probably function by autocrine or paracrine mechanisms during most of gestation $(72,146-148)$. In this milieu conventional endocrine control systems are largely redundant, and other transient systems more appropriate to the intrauterine environment have evolved. We have developed some insights into these systems, but much more information is necessary before we can truly understand this fascinating environment.

Table II. Summary of Fetal Endocrine Systems

\begin{tabular}{|c|c|c|c|c|c|c|}
\hline \multicolumn{2}{|c|}{ Unique fetal hormones } & \multicolumn{2}{|c|}{$\begin{array}{l}\text { Extrahypothalamic } \\
\text { neuropeptides }\end{array}$} & \multirow{2}{*}{$\frac{\text { Prominent fetal hormone species }}{\text { Various sources }}$} & \multicolumn{2}{|c|}{ Neutralized hormone effects } \\
\hline Placenta & Other sources & Placenta & Gut & & Inactive metabolites & Immature receptor systems \\
\hline $\mathrm{hCG}$ & AVT & TRH & TRH & Calcitonin & Cortisone & $T_{3}$ \\
\hline hCS & MIF & SRIF & SRIF & Norepinephrine & $\mathbf{r T}_{3}$ & Growth hormone \\
\hline hCT & $\mathrm{hCG}$ & CRF & CRF & $\alpha-\mathbf{M S H}$ & & Prolactin \\
\hline $\mathrm{hCC}$ & $\mathrm{hCC} ?$ & GnRH & & $\beta$-Endorphin & & Estrogens? \\
\hline \multirow[t]{5}{*}{ Estriol } & & GRF & & DHAS & & \\
\hline & & & & Estradiol & & \\
\hline & & & & Estrone & & \\
\hline & & & & Progesterone & & \\
\hline & & & & OVT & & \\
\hline
\end{tabular}

Abbreviations are as given in footnote 1 and throughout text. 


\section{References}

1. Diczfalusy, E. 1977. In Current Developments in Perinatology. F. Z. Zuspan, editor. C. V. Mosby, St. Louis. 224-238.

2. Lauritzen, C., and A. Klopper. 1983. In Endocrinology of Pregnancy. F. Fuchs and A. Klopper, editors. Harper and Row, Philadelphia. 73-91.

3. Ryan, K. J. 1980. In Maternal Fetal Endocrinology. D. Tulchinsky and K. J. Ryan, editors. W. B. Saunders Co., Philadelphia. 3-16.

4. Buster, J. E. 1983. Clin. Perinatol. 10:527-552.

5. Jaffe, R. B. 1983. Clin. Perinatol. 10:669-693.

6. Simpson, E. R., and P. C. MacDonald. 1981. Annu. Rev. Physiol. 43:163-188.

7. Peterson, R. E. 1983. In Endocrinology of Pregnancy. F. Fuchs and A. Klopper, editors. Harper and Row, Philadelphia. 3rd edition. 112-143.

8. Scoggins, B. A., A. Butkus, J. P. Coghlan, D. T. W. Fei, J. G. McDougall, H. D. Niall, and X. M. Wang. 1984. 7th Int. Congr. Endocrinol. Excerpta Med. Int. Congr. Ser. 124. (Abstr.)

9. Davies, J. 1980. In Maternal Fetal Endocrinology. D. Tulchinsky and K. J. Ryan, editors. W. B. Saunders Co., Philadelphia. 242-251.

10. Ryan, K. J. 1980. In Maternal Fetal Endocrinology. D. Tulchinsky and K. J. Ryan, editors. W. B. Saunders, Philadelphia. 297-309.

11. Challis, J. R. G., B. F. Mitchell, S. G. A. Power, and S. J. Lye. 1985. In Research in Perinatal Medicine. IV. Perinatal Endocrinology. E. Albrecht and G. J. Pepe, editors. Perinatology Press, Ithaca, NY. 263273.

12. Thorburn, G. D., and J. R. G. Challis. 1979. Physiol. Rev. 59: 863-918.

13. Casey, M. L., C. A. Winkel, J. C. Porter, and P. C. MacDonald. 1983. Clin. Perinatol. 709-721.

14. Murphy, B. E. P. 1983. Endocr. Rev. 4:150-154.

15. Murphy, B. E. P., and C. T. LaPlante-Branchaud. 1983. Curr. Top. Exp. Endocrinol. 5:197-229.

16. Liggins, G. C. 1976. Am. J. Obstet. Gynecol. 126:931-939.

17. Liggins, G. C., and J. C. Schellenberg. 1985. In The Physiologic Development of The Fetus and Newborn. C. T. Jones and P. W. Nathanielsz, editors. Academic Press, Ltd., London. 179-189.

18. Cheng, J. B., A. Goldfein, P. L. Ballard, and J. M. Roberts. 1980. Endocrinology. 107:1646-1648.

19. Devaskar, S. V., S. Ganguli, V. P. Devaskar, and M. A. Sperling. 1982. Am. J. Physiol. (Endocr. Metab.) 5:E384-E391.

20. Sadiq, H. F., and V. P. Devaskar. 1984. Biochem. Biophys. Res. Commun. 119:408-414.

21. Wu, W. Y., A. H. Klein, I. J. Chopra, and D. A. Fisher. 1978. Endocrinology. 103:235-239.

22. Clyman, R. I., F. Mauray, C. Roman, A. M. Rudolph, and

M. A. Heymann. 1981. J. Pediatr. 98:126-128.

23. Werlin, S. L., and J. Stefaniak. 1982. Pediatr. Res. 16:123-125.

24. Guiraldes, E., D. G. Gall, and J. R. Hamilton. 1981. Pediatr. Res. 15:1530-1532.

25. Henning, S. J. 1979. Environ. Health Perspect. 33:9-16.

26. Wilson, J. D. 1978. Annu. Rev. Physiol. 40:279-306.

27. Grumbach, M. M., and F. A. Conte. 1985. In Textbook of Endocrinology. J. D. Wilson and D. W. Foster, editors. W. B. Saunders Co., Philadelphia. 7th edition. 312-401.

28. Josso, N., J. Y. Picard, and D. Tran. 1977. Recent Prog. Horm. Res. 33:117-163.

29. Donahoe, P. K., G. P. Budzik, R. Trelstad, M. Mudgett-Hunter, A. Fuller, Jr., J. M. Hutson, H. Ikawa, A. Hayashi, and D. MacLaughlin. 1982. Recent Prog. Horm. Res. 38:279-326.

30. Picard, J. Y., and N. Josso. 1984. Mol. Cell. Endocrinol. 34:2329.

31. Hutson, J. M., M. E. Fallat, S. Kamagata, P. K. Donahoe, and G. P. Budzik. 1984. Science (Wash. DC). 223:586-588.

32. Ikawa, H., J. W. Hutson, G. P. Budzik, and P. K. Donahoe. 1984. Endocrinology. 114:1686-1691.

33. Fisher, D. A. 1983. Clin. Perinatol. 10:695-707.
34. Perks, A. M. 1977. Am. Zool. 17:833-849.

35. Pavel, S. 1978. J. Neural Transm. 13(Suppl.):135-155.

36. Ervin, M. G., R. D. Leake, M. G. Ross, G. C. Calvario, and

D. A. Fisher. 1985. J. Clin. Invest. 75:1696-1701.

37. Bell, R. J., M. Congiu, K. J. Hardy, and E. M. Wintour. 1984.

Q. J. Exp. Physiol. 69:187-195.

38. Daniel, S. S., R. I. Stark, M. K. Husain, L. V. Baxi, and L. S. James. 1982. Am. J. Physiol. (Renal Fluid Electrolytes) 11:740-744.

39. Leake, R. D., H. Stegner, S. M. Palmer, G. K. Oakes, and D. A. Fisher. 1983. Pediatr. Res. 17:583-586.

40. Ross, M. G., M. G. Ervin, R. D. Leake, P. Fu, and D. A. Fisher.

1984. Am. J. Obstet. Gynecol. 150:421-425.

41. Ervin, M. G., M. G. Ross, R. D. Leake, and D. A. Fisher. 1986.

Endocrinology. 118:759-765.

42. Perks, A. M., and S. Cassin. 1982. Chest. 81(Suppl.):635-655.

43. Manku, M. S., J. P. Mtabaji, and D. F. Horrobin. 1975. Nature

(Lond.). 258:78-80.

44. DeVane, G. W., R. P. Naden, J. C. Porter, and C. R. Rosenfeld. 1982. Pediatr. Res. 16:504-507.

45. Stark, R. I., S. S. Daniel, M. K. Hussain, U. M. Sanocka, A. B.

Zubrow, and L. S. James. 1984. Pediatr. Res. 18:552-558.

46. Stegner, H., R. D. Leake, S. M. Palmer, G. Oakes, and D. A.

Fisher. 1984. Pediatr. Res. 18:188-191.

47. DeVane, G. W., and J. C. Porter. 1980. J. Clin. Endocr. Metab. 51:1412-1416.

48. Kelly, R. T., J. C. Rose, P. J. Meis, B. Y. Hargrave, and M. Morris. 1983. Am. J. Obstet. Gynecol. 146:807-812.

49. Comline, R. S., and M. Silver. 1966. Br. Med. Bull. 22:16-20.

50. Jones, C. T., and J. W. Knox Ritchie. 1983. J. Dev. Physiol. 5: 211-222.

51. Stark, R. I., and A. G. Frantz. 1983. Clin. Perinatol. 10:653667.

52. Glatz, T. H., R. E. Weitzman, P. W. Nathanielsz, and D. A. Fisher. 1980. Endocrinology. 106:1006-1011.

53. Glatz, T. H., R. E. Weitzman, R. J. Eliot, A. H. Klein, P. W. Nathanielsz, and D. A. Fisher. 1981. Endocrinology. 108:1328-1332.

54. Leake, R. D., R. E. Weitzman, T. H. Glatz, and D. A. Fisher. 1981. J. Clin. Endocr. Metab. 53:730-733.

55. Leake, R. D., R. E. Weitzman, and D. A. Fisher. 1981. Biol. Neonate. 39:127-131.

56. Weitzman, R. E., R. D. Leake, R. T. Rubin, and D. A. Fisher. 1980. J. Clin. Endocr. Metab. 51:836-839.

57. Leake, R. D., C. B. Waters, R. T. Rubin, J. E. Buster, and D. A. Fisher. 1983. Obstet. Gynecol. 62:565-568.

58. Amico, J. A., M. G. Ervin, R. D. Leake, D. A. Fisher, F. M. Finn, and A. G. Robinson. 1985. J. Clin. Endocr. Metab. 60:5-12.

59. Amico, J. A., M. G. Ervin, F. M. Finn, R. D. Leake, D. A. Fisher, and A. G. Robinson. Metab. Clin. Exp. In press.

60. Ervin, M. G., J. A. Amico, R. D. Leake, M. G. Ross, A. G. Robinson, and D. A. Fisher. Am. J. Obstet. Gynecol. In press.

61. Schedewie, H. K., and D. A. Fisher. 1980. In Maternal Fetal Endocrinology. D. Tulchinsky and K. J. Ryan, editors. W. B. Saunders Co., Philadelphia. 355-386.

62. Pitkin, R. M. 1985. Am. J. Obstet. Gynecol. 151:99-109.

63. Bouillon, P., and F. A. Van Assche. 1982. Dev. Pharmacol. Ther. 4(Suppl.):38-44.

64. Care, A. D., I. W. Caple, and D. W. Pickard. 1985. In The Physiological Development of The Fetus and Newborn. C. T. Jones and P. W. Nathanielsz, editors. Academic Press, Ltd., London. 135-140.

65. Moore, E. S., C. B. Langman, M. J. Favus, and F. L. Coe. 1985.

Pediatr. Res. 19:566-569.

66. Norman, A. W., J. Roth, and L. Orci. 1982. Endocr. Rev. 3:331366.

67. Austin, L. A., and H. Heath. 1981. N. Engl. J. Med. 304:269278.

68. Coupland, R. S. 1952. J. Anat. 86:357-372.

69. Niemineva, K., and A. Pekkarinen. 1952. Ann. Med. Exp. Biol. Fenn. 30:274-286. 
70. Lewis, A. B., W. N. Evans, and W. Sischo. 1982. Biol. Neonate. 41:115-122.

71. Palmer, S. M., G. K. Oakes, J. A. Champion, D. A. Fisher, and C. J. Hobel. 1984. Am. J. Obstet. Gynecol. 149:426-434. 893.

72. Lagercrantz, H., and P. Bistoletti. 1977. Pediatr. Res. 11:889-

73. Irestedt, L., H. Lagercrantz, P. Hjemdahl, K. Hagnevik, and P. Belfrage. 1982. Am. J. Obstet. Gynecol. 142:1004-1010.

74. Padbury, J. F., B. Roberman, T. H. Oddie, C. J. Hobel, and D. A. Fisher. 1982. Obstet. Gynecol. 60:607-611.

75. Newnham, J. P., C. J. Marshall, J. F. Padbury, R. W. Lam, and D. A. Fisher. 1984. Am. J. Obstet. Gynecol. 149:888-893.

76. Gospodarowicz, D. 1981. Annu. Rev. Physiol. 43:251-263.

77. Aloe, L., and R. Levi-Montalcini. 1979. Proc. Natl. Acad. Sci. USA. 76:1246-1250.

78. Visser, M., and D. F. Swaab. 1979. J. Dev. Physiol. 1:161-178.

79. Perry, R. A., H. M. Mulvogue, I. C. McMillen, and P. M. Robinson. 1985. J. Dev. Physiol. 7:397-404.

80. Silman, R. E., T. Chard, P. J. Lowry, I. Smith, and I. M. Young. 1976. Nature (Lond.). 260:716-718.

81. Silman, R. E., D. Holland, T. Chard, P. J. Lowry, and J. Hope. 1978. Nature (Lond.). 276:526-528.

82. Osamura, R. Y., Y. Tsutsumi, and K. Watanake. 1984. J. Histochem. Cytochem. 32:885-893.

83. Glickman, J. A., G. D. Carson, and J. R. G. Challis. 1979. Endocrinology. 104:34-39.

84. Swaab, D. F., and J. T. Martin. 1981. Peptides. 81:196-217.

85. Saxena, B. 1983. In Endocrinology of Pregnancy. F. Fuchs and

A. Klopper, editors. Harper and Row, Philadelphia. 3rd edition. 50-72.

86. Josimovich, J. B. 1983. In Endocrinology of Pregnancy. F. Fuchs and A. Klopper, editors. Harper and Row, Philadelphia. 3rd edition. 144-160.

87. Osathanondh, R., and D. Tulchinsky. 1980. In Maternal Fetal Endocrinology. D. Tulchinsky and K. J. Ryan, editors. W. B. Saunders Co., Philadelphia. 17-42.

88. Fiddes, J. C., and K. Talmadge. 1984. Recent Prog. Horm. Res. 40:43-74.

89. Cooke, N. E., D. Cort, J. Shine, J. D. Baxter, and J. A. Martial. 1981. J. Biol. Chem. 256:4007-4016.

90. Barsh, G. S., P. H. Seeburg, and R. E. Gelinas. 1983. Nucleic Acid Res. 11:3939-3985.

91. Chakravarti, A., J. A. Phillips, K. H. Mellits, K. H. Buetow, and P. H. Seeburg. 1984. Proc. Natl. Acad. Sci. USA. 81:6085-6089.

92. Genazzani, A. R., J. P. Felber, and P. Fioretti. 1976. Acta Endocrinol. 83:800-810.

93. Liotta, A., R. Osathanondh, K. J. Ryan, and D. T. Krieger. 1977. Endocrinology. 101:1552-1558.

94. Odagiri, E. M., B. J. Sherrell, C. D. Mount, W. E. Nicholson, and D. N. Orth. 1979. Proc. Natl. Acad. Sci. USA. 76:2027-2031.

95. Nakai, Y., K. Nakao, S. Oki, and H. Imura. 1978. Life Sci. 23: 2013-2018.

96. Hodgen, G. D., B. J. Gulyas, and W. W. Tullner. 1975. Steroids. 26:233-240.

97. Hennen, G., J. G. Pierce, and P. Freychet. 1969. J. Clin. Endocr. Metab. 29:581-594.

98. Hershman, J. M., and W. R. Starnes. 1969. J. Clin. Invest. 48: 923-929.

99. Harada, A., J. M. Hershman, A. W. Reed, G. D. Braunstein, W. J. Dignam, C. Derzko, S. Friedman, R. Jewelewicz, and A. E. Pekary. 1979. J. Clin. Endocr. Metab. 48:793-797.

100. McGregor, W. G., W. J. Raymoure, R. W. Kuhn, and R. B. Jaffe. 1981. J. Clin. Invest. 68:306-309.

101. McGregor, W. G., R. W. Kuhn, R. B. Jaffe. 1983. Science (Wash. DC). 220:306-308.

102. Goldsmith, P. C., W. G. McGregor, W. J. Raymoure, R. W. Kuhn, and R. B. Jaffe. 1983. J. Clin. Endocr. Metab. 57:654-661.
103. Kapeala, L. P. 1985. Life Sci. 37:2283-2290.

104. Jackson, M. D. 1982. N. Engl. J. Med. 306:145-155.

105. Reichlin, S. 1983. N. Engl. J. Med. 309:1495-1501 and 309: 1556-1563.

106. Shibasaki, T., Y. Kiyosawa, A. Masuda, M. Nakahara, T. Imaki, I. Wakabayashi, H. Demura, K. Shizume, and N. Ling. 1984. J. Clin. Endocr. Metab. 59:263-268.

107. Suda, T., N. Tomori, F. Tozawa, T. Mouri, H. Demura, and K. Shizume. 1984. J. Clin. Endocr. Metab. 59:861-866.

108. Siler-Khodr, T. M. 1983. Clin. Perinatol. 10:553-566.

109. Krieger, D. T. 1982. Biol. Reprod. 26:55-71.

110. Shibasaki, T., E. Odagiri, K. Shizume, and N. Ling. 1982. J. Clin. Endocr. Metab. 55:384-386.

111. Sasaki, A., A. S. Liotta, M. M. Luckey, A. N. Margioris, T. Suda, and D. T. Krieger. 1984. J. Clin. Endocr. Metab. 59:812-814.

112. Baird, A., W. B. Wehrenberg, P. Bohlen, and N. Ling. 1985. Endocrinology. 117:1598-1601.

113. Iwashita, M., M. I. Evans, and K. J. Catt. 1986. J. Clin. Endocr. Metab. 62:127-133.

114. Engler, P., M. F. Scanlon, and I. M. D. Jackson. 1981. J. Clin. Invest. 67:800-808.

115. Koshimizo, T., Y. Ohyama, Y. Yokota, and K. Ohtsuka. 1985. J. Clin. Endocr. Metab. 61:78-82.

116. Hotta, M., T. Shibasaki, A. Masuda, T. Imaki, and N. Obara. 1985. Proceedings of the Endocrine Society Meeting. Endocrine Society, Bethesda, MD. Abstract 1001.

117. Lambertin, P., P. Wu, and I. M. D. Jackson. 1985. Endocrinology. 117:1834-1838.

118. Fisher, D. A. 1983. Clin. Perinatol. 10:615-626.

119. Perelman, A. H., A. H. Klein, and D. A. Fisher. 1981. Clin. Res. 29:111A. (Abstr.)

120. Koivusalo, F. 1981. J. Clin. Endocr. Metab. 53:734-736.

121. Gluckman, P., M. M. Grumbach, and S. L. Kaplan. 1981. Endocrine Rev. 2:363-395.

122. Gluckman, P. D., M. M. Grumbach, and S. L. Kaplan. 1980. In Maternal Fetal Endocrinology. D. Tulchinsky and K. J. Ryan, editors. W. B. Saunders Co., Philadelphia. 196-232.

123. Letarte, J., and S. LaFranchi. 1983. In Congenital Hypothyroidism. J. H. Dussault and P. Walker, editors. Marcel Dekker, New York. 351-383.

124. LaFranchi, S. H., C. E. Hanna, P. L. Krainz, M. R. Skeels, R. S. Miyahira, and D. E. Sesser. 1985. Pediatrics. 76:734-740.

125. Fisher, D. A., and A. H. Klein. 1981. N. Engl. J. Med. 304: 702-712.

126. Guyda, H. J. 1983. In Congenital Hypothyroidism. J. H. Dussault and P. Walker, editors. Marcel Dekker, Inc., New York. 385-396.

127. Glorieux, J., J. H. Dussault, J. Morissette, M. Desjardins, J. Letarte, and H. Guyda. 1985. J. Pediatr. 107:913-915.

128. New England Congenital Hypothyroid Collaborative. 1985. J. Pediatr. 107:915-919.

129. Roti, E., A. Gnudi, and L. E. Braverman. 1983. Endocr. Rev. 4:131-149.

130. Fisher, D. A., J. H. Dussault, J. Sack, and I. J. Chopra. 1977. Recent Prog. Horm. Res. 33:59-116.

131. Chopra, I. J., J. Sack, and D. A. Fisher. 1975. Endocrinology. 97:1080-1088.

132. Kaplan, M. M. In Congenital Hypothyroidism. J. H. Dussault and P. Walker, editors. Marcel Dekker, Inc., New York. 11-35.

133. Klein, A. H., A. Reviczky, J. F. Padbury, and D. A. Fisher. 1983. Am. J. Physiol. (Endocr. Metab.) 7:E603-E606.

134. Padbury, J. F., A. H. Klein, D. H. Polk, R. W. Lam, C. J. Hobel, and D. A. Fisher. 1986. Pharmacol. Ther. 9:44-53.

135. Coulombe, P., J. Ruel, and J. H. Dussault. 1980. Endocrinology. 107:2027-2033.

136. Lakshmanan, J., U. Beri, J. Perheentupa, T. Macaso, and D. A. Fisher. 1984. J. Neurosci. Res. 12:71-85. 
137. Lakshmanan, J., J. Perheentupa, T. Macaso, and D. A. Fisher. Acta Endocrinol. In press.

138. Alm, J., S. M. Scott, and D. A. Fisher. 1986. J. Dev. Physiol. In press.

139. Hoath, S. B., J. Lakshmanan, and D. A. Fisher. 1984. Biol. Neonate. 45:49-52.

140. Hoath, S. B., J. Lakshmanan, and D. A. Fisher. 1985. Pediatr. Res. 19:277-280.

141. Perez-Castillo, A., J. Bernal, B. Ferreiro, and T. Pans. 1985. Endocrinology. 117:2457-2461.

142. Gluckman, P. D. 1985. In Physiological Development of the Fetus and Newborn. C. T. Jones and P. W. Nathanielsz, editors. Academic Press, Ltd., London. 103-111.
143. Padbury, J. F., R. W. Lam, J. P. Newnham, and D. A. Fisher. 1984. Clin. Res. 32:127A. (Abstr.)

144. Pasqualini, J. R., C. Sumida, C. Gelly, and B. L. Nguyen. 1976. J. Steroid Biochem. 7:1031-1038. 78.

145. Clark, J. H., and J. Gorski. 1970. Science (Wash. DC). 169:76-

146. Adamson, E. D. 1983. In The Biological Basis of Reproductive and Developmental Medicine. J. B. Warshaw, editor. Elsevier-North Holland, Inc. New York. 307-336.

147. D'Ercole, A. J., and L. E. Underwood. 1981. In Fetal Endocrinology. M. J. Novy and J. A. Resko, editors. Academic Press, Inc., New York. 155-182.

148. Fisher, D. A. 1985. In Pediatric Thyroidology. F. Delange, D. A. Fisher, and P. Malvaux, editors. S. Karger, Basel. 75-89. 